\title{
AS FACES DO AGRONEGÓCIO MARANHENSE: UMA ANÁLISE DA EXPANSÃO AGRÍCOLA E DO AUMENTO DA VIOLÊNCIA NO CAMPO
}

\author{
Ronaldo Barros Sodré ${ }^{1}$ \\ Juscinaldo Goes Almeida² \\ Igor Breno Barbosa de Sousa ${ }^{3}$ \\ Tibério Augusto Santos de Souza ${ }^{4}$ \\ José Sampaio de Mattos Júnior ${ }^{5}$
}

Resumo: As relações capitalistas no campo são geradoras de territórios com lógicas distintas e contraditórias, assim a produção agrícola nesses territórios nos possibilita diferenciá-los e relacioná-los com as questões sociais no campo. Nessa perspectiva, valemo-nos do Materialismo Histórico Dialético para a construção dessa pesquisa tendo como recorte o estado do Maranhão e o auxílio de dados do IBGE e da CPT. Com isto, discutimos a produção das lavouras, produtos da extração vegetal e da silvicultura, e relacionamos com a violência, compreendendo que a expansão do agronegócio maranhense é um dos principais responsáveis pelo aumento da violência contra camponeses e trabalhadores rurais. Por fim, consideramos a manutenção da estrutura fundiária como principal fator desta configuração espacial.

Palavras-chave: Agronegócio. Maranhão. Produção agrícola. Violência.

\section{THE FACES OF MARANHENSE AGRIBUSINESS: AN ANALYSIS OF AGRICULTURAL EXPANSION AND THE INCREASE OF VIOLENCE IN THE COUNTRYSIDE}

Abstract: The capitalist relations in the countryside are generate territories with distinct and contradictory logics, thus the agricultural production in these territories enable us to differentiate them and relate them to social questions in the countryside. In this perspective, we use the Dialectical Historical Materialism for the construction of this research having as a cut the state of Maranhão and the aid of data from IBGE and CPT. With this, we discuss the production of crops, products of plant extraction and forestry, and relate to violence, understanding that the expansion of maranhense agribusiness is one of the main responsible for the increase of violence against peasants and rural workers. Finally, we consider the maintenance of the land structure as the main factor of this spatial configuration.

Keywords: Agribusiness. Maranhão. Agricultural production. Violence.

\section{LAS CARAS DEL AGRONECOCIO MARANHENSE: UN ANÁLISIS DE LA EXPANSION AGRÍCOLA Y DEL AUMENTO DE LA VIOLENCIA EN EL CAMPO}

Resumen: Las relaciones capitalistas en el campo son generadoras de territorios con logicas distintas y contradictorias. A partir de la producción agrícola de esos

\footnotetext{
1 Universidade Federal do Pará, Instituto de Filosofia e Ciências Humanas, Belém, Brasil, ronaldosodr@hotmail.com, https://orcid.org/0000-0002-4643-2103

2 Universidade Estadual do Maranhão, Departamento de História e Geografia, São Luís, Brasil, juscinaldogoes@hotmail.com, https://orcid.org/0000-0002-1825-0097

3 Universidade Estadual do Maranhão, Departamento de História e Geografia, São Luís, Brasil, iggor_brenol@gmail.com, https://orcid.org/0000-0002-2273-2945

4 Universidade Estadual do Maranhão, Departamento de História e Geografia, São Luís, Brasil, tiberioaugustoo@outlook.com, https://orcid.org/0000-0002-7887-8927

${ }^{5}$ Universidade Estadual do Maranhão, Departamento de História e Geografia, São Luís, Brasil, sampaio.uema@gmail.com, https://orcid.org/0000-0003-0593-7612
} 
territorios es posible diferenciarlos y relacionarlos con las cuestiones sociales en el campo. En esa perspectiva, nos valemos del Materialismo Histórico Dialéctico para la construcción de esa investigación teniendo como recorte el estado de Maranhão y la ayuda de datos del IBGE y de la CPT. Con esto, discutimos la producción de los cultivos, productos de la extracción vegetal y de la silvicultura, y relacionamos con la violencia, comprendiendo que la expansión del agronegocio maranhense es uno de los principales responsables por el aumento de la violencia contra campesinos y trabajadores rurales. Por último, consideramos el mantenimiento de la estructura agraria como principal factor de esta configuración espacial.

Palabras clave: Agronegocio. Maranhão. Produción agrícola. Violencia.

\section{Introdução}

A Geografia Agrária brasileira surge da cisão dos estudos agrícolas e agrários, que refletem fundamentos teóricos-metodológicos distintos. Já na década de 1960 os estudos de Orlando Valverde mostraram maior abrangência da questão agrária em relação à agrícola, sobretudo, pela essência das relações sociais que são inerentes a agricultura (PAULINO, 2007). Não é nosso objetivo nesse texto discutir tal dissidência, mas demonstrar que as questões relacionadas a produção agrícola estão indubitavelmente relacionadas às questões agrárias, principalmente quando nos referimos ao agronegócio como uma das facetas do capitalismo no campo.

As formas de modernização e a construção de novos ciclos econômicos refletem a priorização das políticas públicas para a agroexportação, a partir de um conjunto de ações (subsídios, créditos, infraestrutura entre outros) que visam o estabelecimento de um modelo hegemônico para o campo brasileiro. A manutenção do território do agronegócio tem em vista a sua expansão territorial e uma das formas mais usuais é por meio da concentração fundiária, pois a manutenção e expansão da estrutura fundiária e produtiva são fundamentais para o desenvolvimento do capitalismo no campo. De acordo com Girardi (2008, p.250) a tendência é que o agronegócio se expanda cada vez mais, pois a participação do Brasil no capitalismo mundial é por meio da exportação de produtos, situação essa, fruto da divisão internacional do trabalho e das formas como o país tem sido governado.

Nesta perspectiva de consolidação do capitalismo no campo, temos como lócus de pesquisa o estado do Maranhão (Mapa 01), isso não significa aparta-lo do contexto do agronegócio brasileiro atual nem tampouco isolar estas últimas décadas da historicidade do Brasil Colônia e do Brasil Império, pois as práticas 
agroexportadoras apenas se remodelam, isto é, se modificam de acordo com as demandadas do mercado.

\section{Mapa 01: Localização do estado do Maranhão}

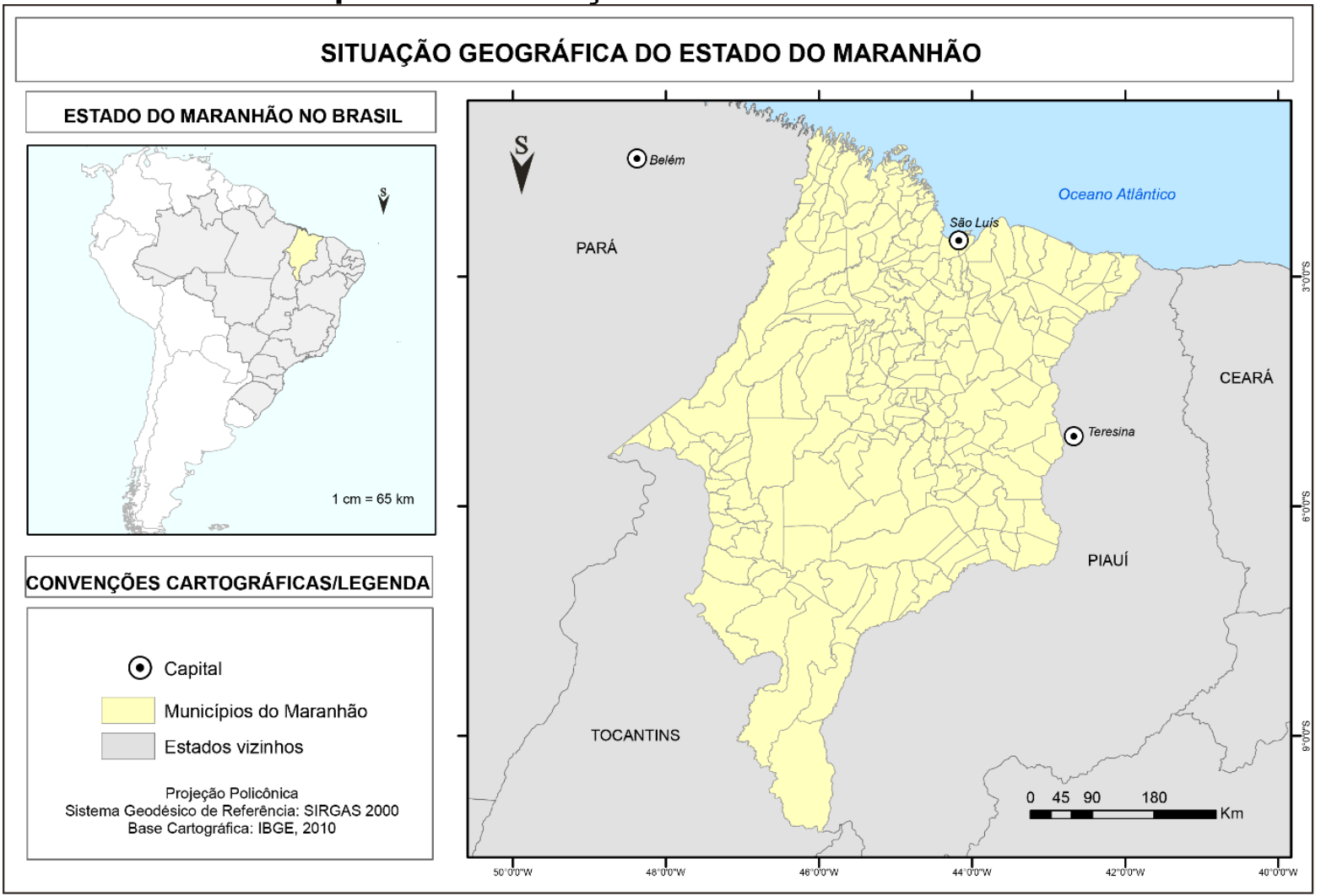

O resultado do conjunto de técnicas e procedimentos utilizados no campo, nos ajudam a decifrar as dinâmicas territoriais e a atual organização do espaço maranhense. Desta forma, buscamos analisar a estrutura produtiva agrícola do Maranhão a partir do levantamento de dados referentes à produção das lavouras permanentes e temporárias; da silvicultura; extração vegetal e relacionamos essa distribuição com a violência no campo, explicitando o que está por trás das relações que se baseiam no modelo produtivista do agronegócio.

Sendo assim, fez-se necessário estruturarmos nossa pesquisa a partir do método do materialismo histórico dialético, haja vista que tal utilização teóricometodológica nos ajuda a entender o campo maranhense como fruto das relações contraditórias e dialéticas de capitalistas e camponeses. Enquanto de um lado, o Maranhão vêm se tornando um notável produtor de commodities, na posição contrária à subordinação neoliberal, os camponeses continuam a manter uma estrutura produtiva agrícola diversificada, mesmo sem contar com os privilégios dado a produção para exportação. Para a realização da pesquisa, temos como principais fontes de dados o Instituto Brasileiro de Geografia e Estatística (IBGE) e a 
Comissão Pastoral da Terra (CPT), além de textos que nos ajudam a compreender as dinâmicas agrícolas e agrários do Maranhão em diferentes momentos.

Nesse sentido, o presente artigo está estruturado da seguinte forma: na primeira parte discutimos os aspectos relacionados a produção do espaço agrário maranhense analisando o valor da produção das lavouras permanentes e temporárias, além da silvicultura e extração vegetal. A segunda parte nos atemos a distribuição das lavouras permanentes e temporárias no território maranhense a partir da análise de dados do IBGE. Em seguida, buscamos compreender a configuração do extrativismo vegetal e da silvicultura e suas distribuições no território maranhense. Na última parte do presente artigo relacionamos os dados referentes às lavouras permanentes e temporárias, silvicultura e extração vegetal, com a violência no campo, explicitando o que está por trás das relações que se baseiam no modelo produtivista do agronegócio.

\section{A produção no espaço agrário maranhense: das lavoura}

A agricultura no Brasil está intimamente ligada de forma histórica ao crescimento econômico do país. Esta, sempre cumpriu papel estratégico no processo de desenvolvimento capitalista, sendo desenhada e redesenhada por políticas econômicas que impulsionaram o processo de modernização e expansão das atividades agrícolas. Tal fato pode ser bem observado na política macroeconômica do pós-64, que esboçou políticas setoriais, a exemplo da política agrícola de modernização, na qual se ofertava credito rural subsidiado a fim de aumentar a oferta e a produtividade por meio de maiores interações entre agricultura e indústria. Em face de tais elementos destacados, Mesquita (2011, p. 36) explicita que:

Ao eleger a agricultura como um dos setores estratégicos de sustentação do modelo econômico, a antiga base de operacionalização da atividade, extensiva e pouco moderna, teve de ser substituída por um novo padrão sustentado na mecanização e quimificação intensiva. A mesma far-se-á através da adoção de modernas tecnologias provenientes de países ricos, com o que a agricultura terá condição de cumprir satisfatoriamente suas funções básicas, já que sua efetivação possibilitaria, em curto prazo, o aumento da produção, da produtividade e do lucro.

Nessa perspectiva, a participação do Estado para a configuração do campo brasileiro nos mostra as disparidades entre a priorização da agricultura empresarial que objetiva a exportação de produtos e um segundo segmento supostamente destinado a receber políticas compensatórias, a agricultura familiar. Tal fato, não é 
de causar nenhum estranhamento dado às características intrínsecas do Estado, que apesar das facetas que pode assumir, ainda é sumariamente de caráter capitalista. Neste sentido, acrescenta-se que é, sobretudo a partir da década de 1980 que as diferenças nessas áreas de produção se alargam, pois, a fim de fomentar a agricultura e contribuir para o crescimento econômico do país, o Estado dedica aos agroexportadores subsídios de crédito e isenções fiscais.

Para tanto, a estrutura do campo maranhense não foge às atenuações da formação socioeconômica e cultural do restante do país. Assim, o Maranhão desde sua época colonial possui em seu trajeto grande alinhamento à demanda externa por produtos agrícolas, tendo destaque no cenário nacional e internacional, mas historicamente, o estado conviveu/convive com as disputas por terras, onde poucos concentram a grande quantidade de terras objetivando a agroexportação e muitos lutam por uma pequena parcela de terra para exercer suas atividades sociais, econômicas, políticas e culturais, ou seja, viver em seu território e preservando sua identidade histórica.

A consolidação da agroindústria no Maranhão teve alguns aspectos que a favorecia, a exemplo disso, destacam-se os baixos preços de terra ${ }^{6}$, estas muitas vezes sendo incorporadas por meio da grilagem e também com a atuação do estado nas expropriações de camponeses ${ }^{7}$. O ascendente avanço da produção após a atuação do agronegócio se mostra significativo e favorável a economia se comparado a décadas anteriores, tal fato seria responsável também pela inclusão social e melhoria da qualidade de vida de forma concomitante ao seu desenvolvimento econômico. No entanto, este se fez de modo isolado, haja vista que os indicadores sociais continuam no pódio dos mais baixos do País.

A partir destas premissas, analisamos o valor da produção das lavouras permanentes e temporárias, silvicultura e extração vegetal. A distribuição espacial é bastante diversificada entre as regiões do estado, contudo, notamos certa concentração nos valores produzidos de uma determinada produção sobre outra. As lavouras temporárias são as que possuem os maiores valores de produção, em

\footnotetext{
${ }^{6}$ No final dos anos 1960, com a promulgação da Lei de Terras (instituída entre 1966 e 1970) pelo governo Sarney estabeleceu-se um vigoroso mercado regional de terras, responsável por um conjunto de transformações nas relações sociais no campo. As terras devolutas atraíram vários grupos econômicos (de dentro e fora do estado), passando a formar sociedades anônimas com áreas de 20.000 a 100.00 mil hectares (BARBOSA, 2006).

7 Wolf (1976) explicita que: "primeiro é que o camponês é aquele que tem acesso a uma parcela de terra para produzir. Segundo é que essa produção se faz fundamentalmente a partir da força de trabalho familiar. Terceiro é que, sendo familiar a unidade camponesa é, a um só tempo, unidade de produção e consumo".
} 
2017 elas geraram $R \$ 4.455 .965,000$ a soja desempenha um papel importante nesse todo, ela foi responsável por adicionar $R \$ 2.322 .178,000$ o que representa $52 \%$ do valor de todas as lavouras temporárias do estado. Os produtos da silvicultura ocupam a segunda posição entre os maiores valores registrados pelo IBGE, o valor foi de $R \$ 291.128,000$. O carvão vegetal de eucalipto foi o produto que mais contribuiu com o total, com $R \$ 130.480,000$ representando $45 \%$ de toda produção da silvicultura (SIDRA - IBGE, 2018).

A extração vegetal maranhense teve um valor de $R \$ 251.727,000$, o carvão vegetal foi 0 produto que mais contribuiu para esses números, foram $R \$$ $130.480,000$, ou seja, $54 \%$ do valor da extração vegetal. Por último, temos as lavouras permanentes, que somaram $R \$ 97.311,000$ em 2017 , o valor das bananas produzidas chegou a $\mathrm{R} \$ 70.646,000$, o que corresponde a $73 \%$ do valor adicionado às lavouras permanentes.

A partir destas observações, pontua-se que o processo de acumulação e reprodução do capital no campo parte, principalmente, da agricultura empresarial fomentada pelo Estado e pelas ações do mercado, ou seja, segundo Mesquita (2011) nos últimos 20 anos há um acréscimo nas áreas plantadas com soja e um decréscimo nas áreas destinadas à produção de alimentos básicos.

\section{A distribuição das lavouras no Maranhão enquanto indicador de territorialidades}

Em 2017 as lavouras temporárias totalizavam 1.835 .782 hectares, as culturas que ocupam as maiores áreas das lavouras temporárias estão ligadas ao agronegócio, como é o caso da soja (45\%) e do milho (26\%), logo em seguida culturas que fazem parte da base da agricultura camponesa maranhense, como 0 arroz $(9 \%)$, a mandioca $(8 \%)$ e o feijão $(4 \%)$. A Prancha 1 nos permite analisar a distribuição de produtos essenciais ao abastecimento das casas maranhenses.

O arroz apresenta maior incidência nas áreas da agricultura camponesa. Apesar de municípios como São Mateus do Maranhão, Arari e Vitória do Mearim despontarem com a produção em algumas médias e grandes propriedades, 0 arroz se destaca como produto da agricultura de subsistência, muito embora já tenha sido um dos principais produtos de exportação do Maranhão, sobretudo por meio da expansão camponesa nas áreas de fronteira da Pré-Amazônia Maranhense, onde a produção rizícola do estado foi considerada uma das maiores do país (ANDRADE, 
1973; SANTOS, 2009; VELHO, 2013). O feijão é outro produto de lavouras temporárias que está intimamente relacionada a agricultura camponesa, ele se concentra, sobretudo, nas microrregiões do Médio Mearim, Presidente Dutra, Chapadinha e Baixo Paranaíba.

A mandioca também está entre os produtos da lavoura temporária plantada por camponeses no Maranhão, matéria prima da farinha, um dos principais produtos da alimentação maranhense, a mandioca apresenta grande quantidade produzida em quase toda área que abrange as mesorregiões Centro e Norte maranhense. Destacam-se as microrregiões de Rosário, Gurupi, Baixada Maranhense, Médio Mearim, Pindaré e Baixo Parnaíba que de acordo com estudos realizados por Silva (2014), além da farinha, se destaca também na produção de tiquira, bebida fabricada a partir da mandioca. Segundo Josué de Castro, a mandioca é o produto básico da Amazônia Brasileira, a farinha de mandioca, regionalmente chamada de farinha d'água, constitui um complemento obrigatório de quase tudo que se come nessa região (CASTRO, 1984).

O milho é uma cultura ligada tanto ao agronegócio (no sul) quanto a agricultura camponesa (nas demais regiões). Nas regiões de plantio de soja, o milho é plantado na entre-safra como forma de rotacionar a terra, por conta do baixo valor do produto, muitas vezes os grandes proprietários permitem que os camponeses utilizem a terra sob a forma de arrendamento ou não, no Leste Maranhense esse tipo de relação pode ser observada com a inclusão de outros produtos como arroz e feijão. 


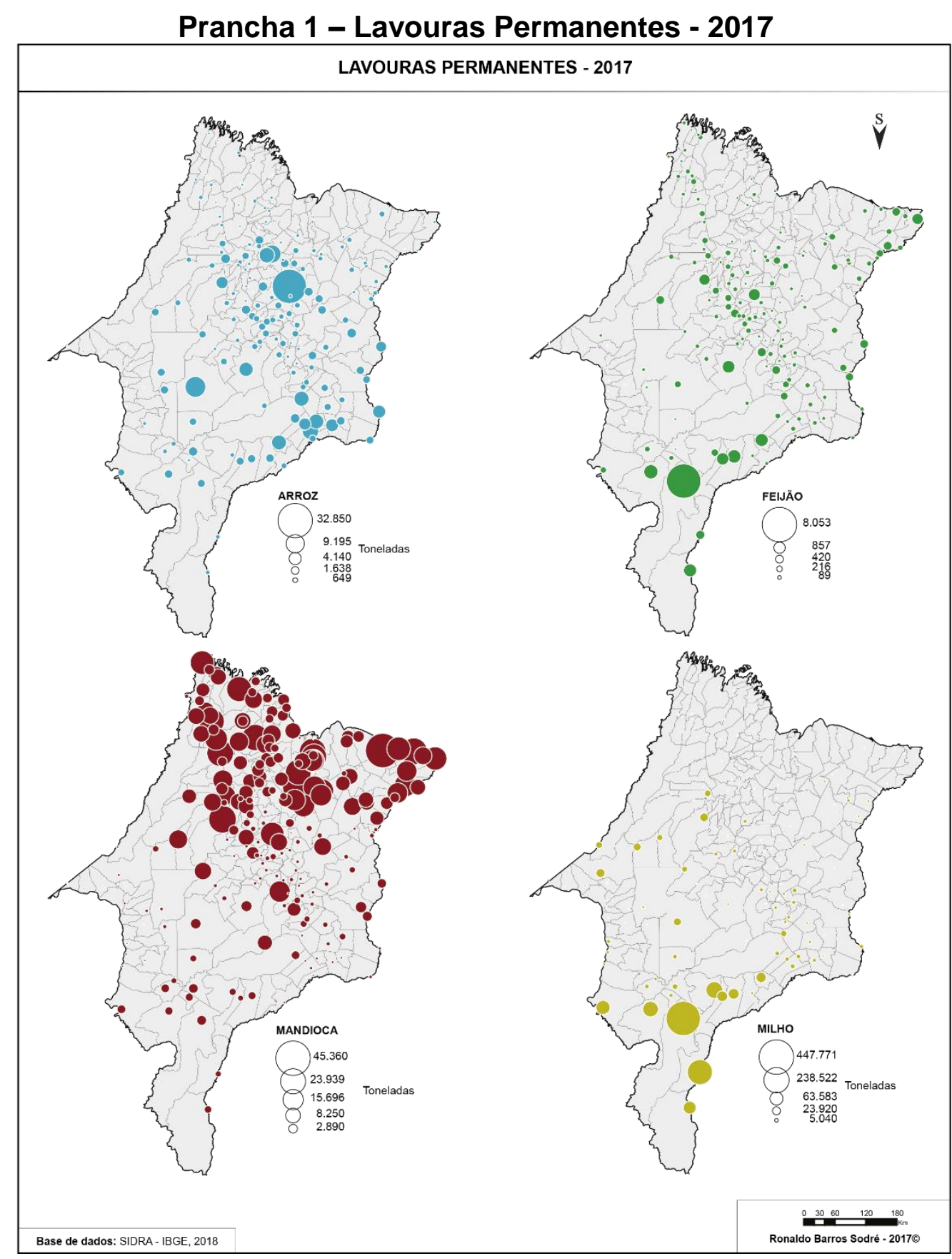

$\mathrm{Na}$ Prancha 2 continuamos analisando produtos das lavouras temporárias que fazem parte do território do agronegócio no Maranhão. Observamos novamente uma territorialização do algodão no sul do estado, notadamente nos municípios de Alto Paranaíba, Balsas e Tasso Fragoso. A cotonicultura vem abastecendo o mercado interno com caroço para ração e oléo, enquanto a fibra abastece o mercado internacional.

De acordo com Sodré (2017), a cana-de-açúcar é outro produto que volta a ser cultivado com maior intensidade no Maranhão. No período recente, o Programa Nacional do Álcool (PROALCOOL), foi o principal responsável pelo aumento do 
cultivo da cana no estado, primeiramente no leste e depois no sul. Atualmente a cana está concetrada nos municípios de Aldeias Altas, Campestre do Maranhão, Coelho Neto, Tuntun e São Raimundo das Mangabeiras, em todos esses municípios existem ao menos uma usina de produção de açúcar ou de álcool.

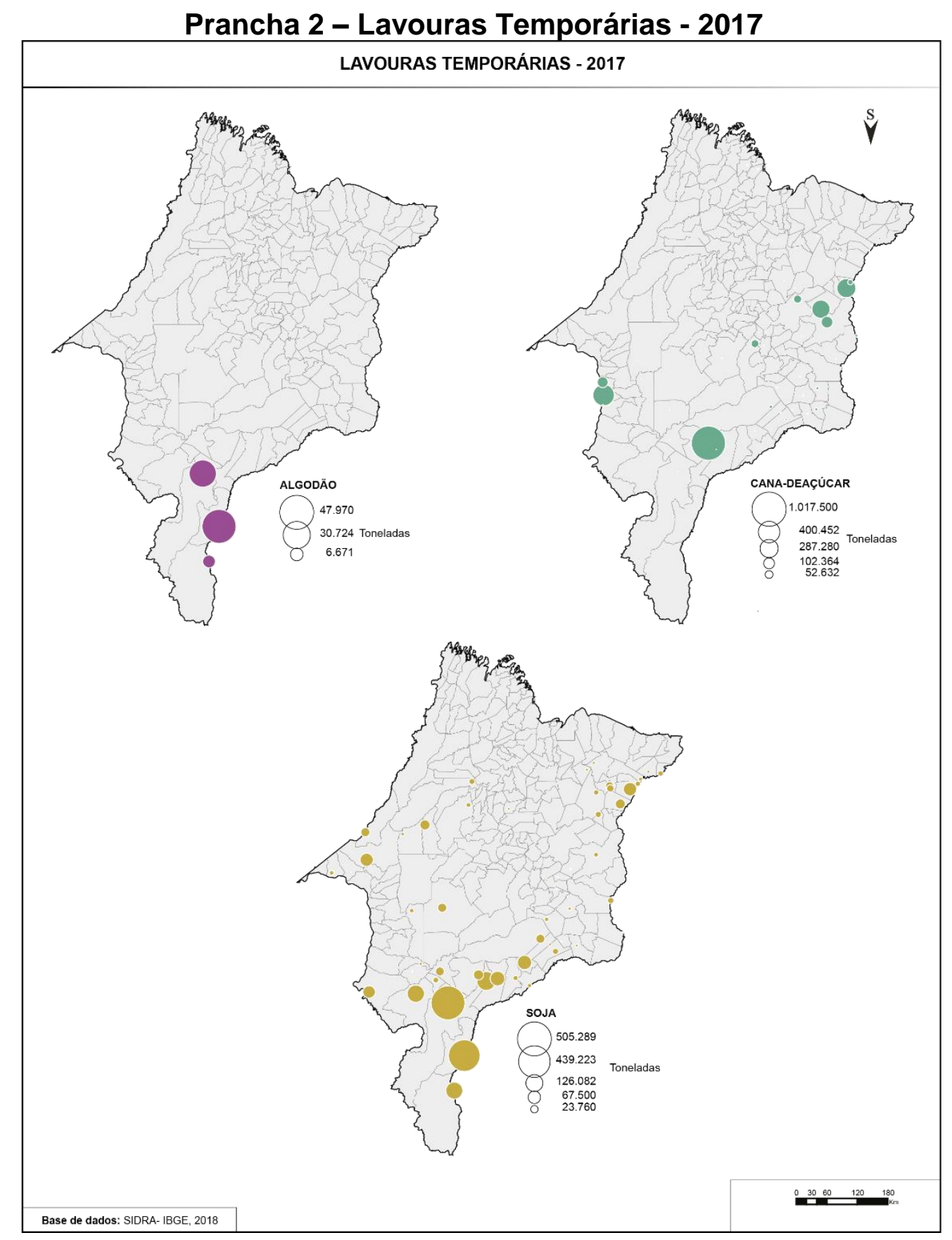

Conforme aponta Girardi (2008), a soja é a cultura mais importante do agronegócio brasileiro e a sua produção pode ser tomada como um indicador na territorialização do agronegócio. A soja em pouco menos de três décadas tornou-se não só a cultura mais importante do agronegócio maranhense, mas, também o produto da agricultura mais importante economicamente do estado. De acordo com 
Carneiro et al (2008), os primeiros cultivos de soja em larga escala em terras maranhenses serão registrados pelo IBGE em 1978. Nos anos noventa a produção sojícola ganhará impulso definitivo, concentrando-se inicialmente na mesorregião sul maranhense (mais precisamente nos municípios de Balsas, Riachão, Tasso Fragoso, S. Raimundo das Mangabeiras e Sambaíba). Nos últimos anos do século XX, a produção de soja se consolida no sul do Maranhão e avança para outras regiões do estado, principalmente para o centro (Grajaú, Formosa da Serra Negra, Fortuna e Fernando Falcão) e o leste maranhense (Chapadinha, Brejo, Anapurus).

Por outro lado, as lavouras permanentes ou de longa duração, possuem baixa produção se compararmos com as lavouras temporárias no Maranhão. Embora as áreas cultivadas sejam muito pequenas, não há esforços de desenvolver a fruticultura, como em outros estados do nordeste oriental. A banana, o coco-da-baía e a laranja são os principais produtos de lavouras permanentes do estado (SODRÉ, 2017).

Essas lavouras são resultantes de unidades demonstrativas da extinta Empresa Maranhense de Assistência Técnica (EMATER). Na década de 1990, por meio da também extinta Companhia de Defesa Agropecuária do Maranhão (CODAGRO), a Secretaria de Agricultura (SAGRIMA) distribuiu mudas e sementes de culturas como a banana, o coco-da-baía e de laranja. Apesar de não ter havido um acompanhamento e maiores esforços por meio dos órgãos estaduais ligados a agricultura, por serem permanentes, muitas dessas lavouras ainda existem, muito embora sua produção seja mínima.

Na Prancha 3 analisamos a distribuição dessas lavouras, a banana está em praticamente todo o Maranhão, com maior concentração no Médio Mearim, o cocoda-baía aparece com mais frequência no norte, nas regiões com maior salinidade. $A$ laranja também está distribuída em praticamente todo o estado, com exceção da Amazônia. As regiões com maior quantidade de frutos são o Médio Mearim e o Baixo Parnaíba. 


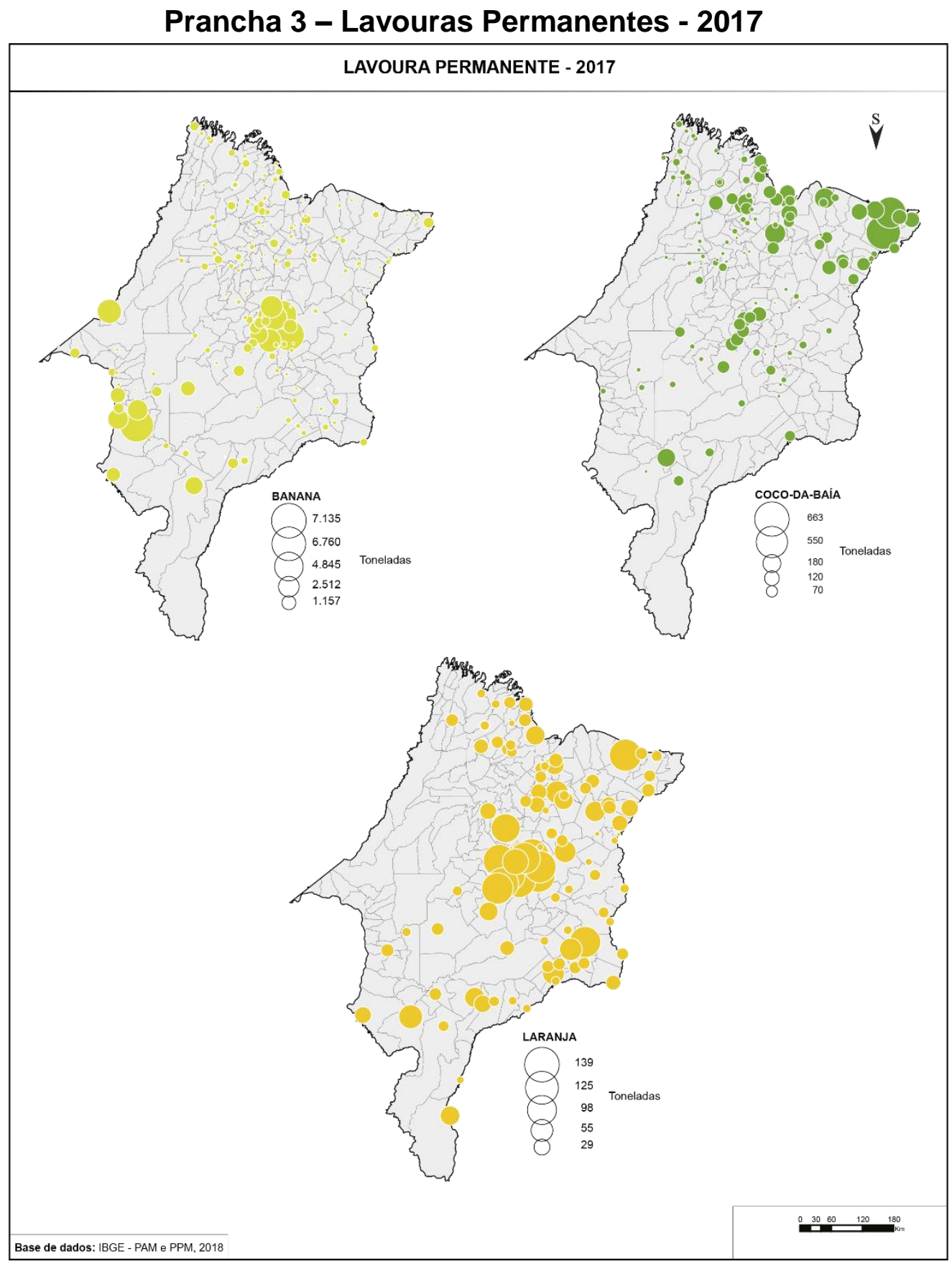

A partir das demonstrações feitas na Figura 3, evidenciamos a existência das lavouras permanentes e dos principais produtos cultivados. Embora o direcionamento de políticas públicas por parte do Estado não impulsione esta prática, tal fato é representativo diante da série histórica dos Censos Agropecuários do IBGE, onde há pelo menos 30 anos atrás, a produção é diagnosticada abaixo dos 500.000 hectares, e se manteve estagnada nos anos 1990 e com um leve acréscimo no ano de 2006, mas ainda abaixo dos 500.000 hectares e, atualmente, perpetua-se abaixo dos 500.000 ha, conforme o Gráfico 1 . 


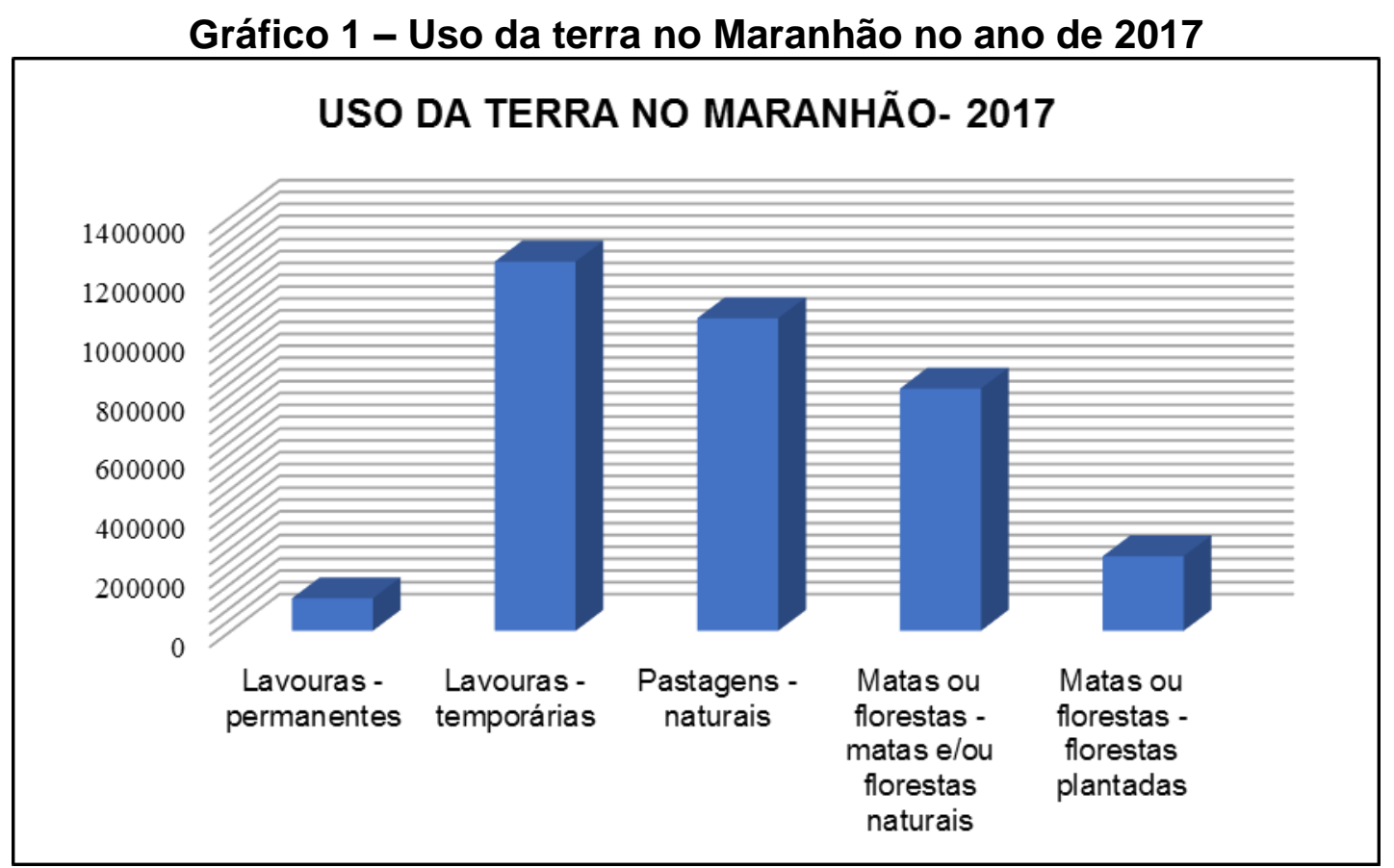

Fonte: Censo Agropecuário - IBGE (2017)

Nesta perspectiva, falar da baixa priorização do Maranhão no que tange ao desenvolvimento da fruticultura, das lavouras permanentes, é também explicado pela priorização do Estado sob a égide neoliberal na década de 1990, onde segundo Mesquita (2011) a agricultura familiar, ainda que conte com o PRONAF e os seus programas auxiliares de créditos, há muito tempo perdeu a corrida para a pecuária, soja e o eucalipto; estas que possuem o quíntuplo e o sêxtuplo da área das lavouras permanentes que estão em processos de expansão vigorosamente.

\section{O território do extrativismo vegetal e a silvicultura no campo maranhense}

A extração de produtos vegetais não cultivados pelo Homem ainda é prática comum entre os camponeses do Maranhão. As florestas que ainda permanecem de pé sustentam uma grande quantidade de trabalhadores que frequentemente entram em conflitos pela preservação dos ecossistemas, tanto do que resta da Amazônia quanto dos cerrados. Girardi (2008, p.263) chama atenção para a distinção extrativismo da floresta e extrativismo na floresta. O extrativismo predatório de madeira é conflitante com o extrativismo praticado pelos povos da floresta, que vivem da exploração dos produtos da floresta e que precisam dela viva.

O extrativismo de madeira está quase inteiramente relacionado a grandes estabelecimentos capitalistas, notamos uma predominância no Oeste, principalmente nas microrregiões do Gurupi e de Pindaré, áreas com alto grau de 
desflorestamento da Amazônia. A falta de aparato da segurança pública torna quase impossível a possibilidade de monitorar e coibir a extração de madeira que abastece as madeireiras e guseiras da região. No leste, o cerrado também vem sendo impactado, o uso de "correntões" para implantação de lavouras para abastecer o mercado tem sido a principal causa desse tipo de extração vegetal. No caso desta região em específico, os desmatamentos para a extração vegetal, sobretudo do cerrado, foram iniciados nos anos 1980 através principalmente das empresas Margusa e Marflora, resultando na eclosão de vários conflitos por terra na região (PAULA ANDRADE, 1995).

O extrativismo de lenha é encontrado em quase todo estado, foge à regra o Oeste, onde, como já observado, predomina outro tipo de extrativismo e de atividades ligadas a silvicultura. $O$ carvão vegetal também está espalhado em todo estado e está ligado a uma produção camponesa, a exceção estar em alguns municípios cortados pela BR-222 no Alto Mearim e Grajaú (SODRÉ, 2017).

$\mathrm{O}$ coco babaçu é um produto historicamente relacionado ao extrativismo vegetal em pequenos estabelecimentos do Maranhão. No século XX ele foi um dos principais produtos da economia maranhense ${ }^{8}$ e causa de muitos conflitos agrários ao longo dos anos.

Atualmente, verificamos que o babaçu vem ganhando uma nova valorização econômica e transformando as relações de trabalho no campo. Se antes as quebradeiras extraíam o coco, quebravam, vendiam a amêndoa, óleo e/ou o carvão, hoje algumas mulheres estão se tornando coletoras de coco para empresas. Ao longo dos anos, o território das quebradeiras vem ganhando representatividade e visibilidade econômica, atualmente ele é o principal produto exportado da agricultura camponesa. As principais regiões de produção de coco babaçu são a Região dos Cocais, Médio Mearim, Itapecuru e Baixada Maranhense. Na Figura 4 temos a espacialização das principais atividades relacionadas ao extrativismo vegetal no Maranhão.

\footnotetext{
8 Conforme Amaral Filho (1990, p. 25) em 1911 o Maranhão exportou pela primeira vez o babaçu para Alemanha, será esse país o principal comprador do produto, principalmente, durante a Primeira Guerra Mundial (1914-1915), quando houve uma desorganização do mercado internacional. Andrade (1984, p. 81) escreve que no período de 1918-1928 diversas empresas estrangeiras se interessaram pelo comércio da oleaginosa e empregaram vultosos capitais, mas em pouco tempo essas empresas verão seus intentos malogrados devido a diversos fatores: desorganização da produção, falta de conhecimentos geoeconômicos nas áreas produtoras, contingências de produção e problemas ligados ao mercado internacional.
} 


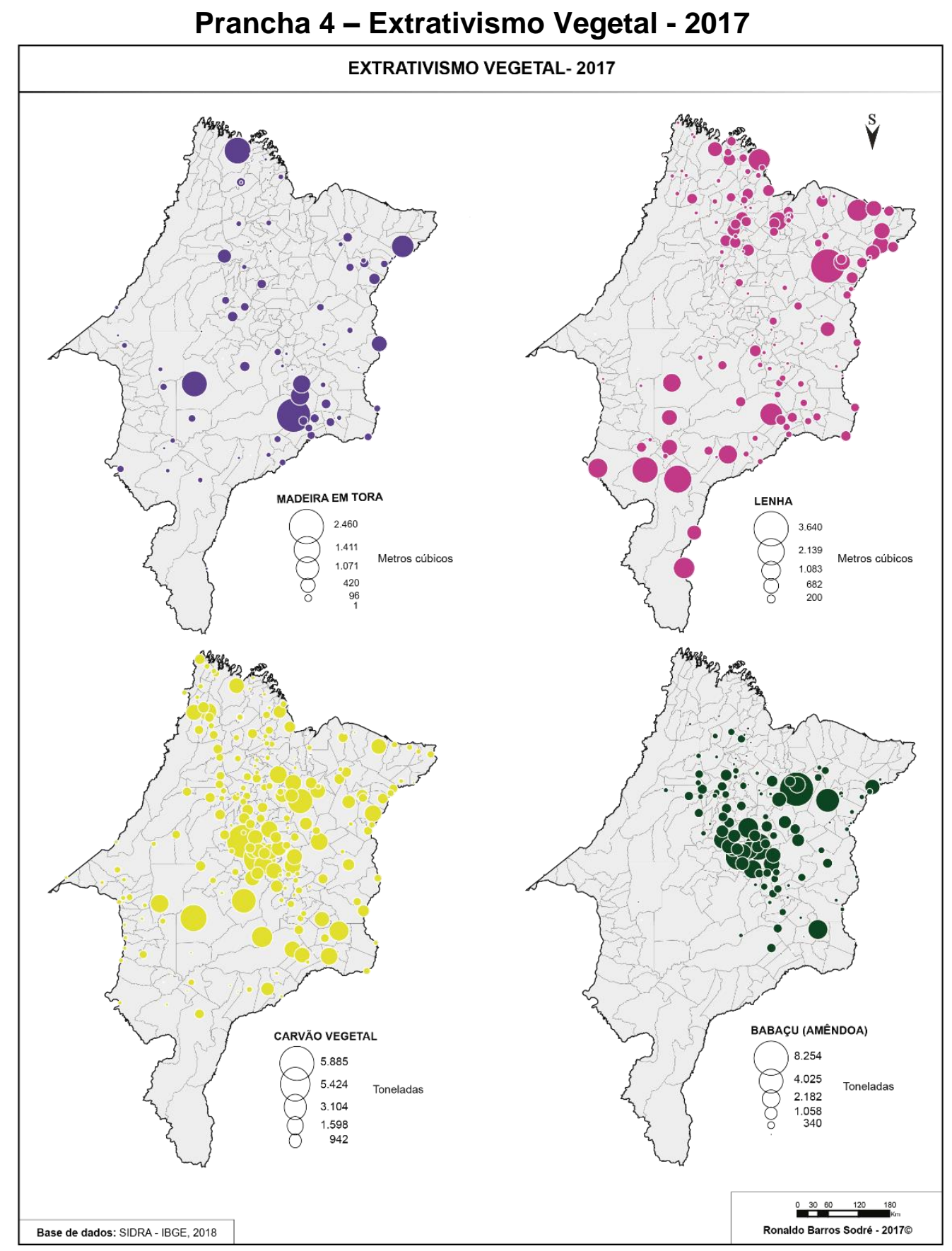

Essa espacialização nos mostra o quão alinhado estão às atividades extrativistas, tanto para pequenos quanto para grandes proprietários. Este tal alinhamento é de decorrência histórica no estado, ou seja, destacar a produção de carvão vegetal, madeira em tora e lenha, apenas refletem a importância destes produtos para o abastecimento ou até mesmo o desenvolvimento de outras atividades capitalistas, principalmente localizadas no meio urbano. Marx (2011) elucidou em seus manuscritos econômicos que produtos como o carvão representam a oportunidade de se eliminar gastos nas atividades fabris, pois, o carvão enquanto matéria-prima nada custa para a produção e nem adiciona absolutamente nada ao valor. 
Ou seja, em outras palavras, a demanda por estas atividades competem, na maioria das vezes, a um caráter de ilegalidade onde se prioriza redução nos gastos de outras atividades capitalistas e a inércia do Estado no que tange à segurança de áreas de preservação, abre a oportunidade para a perpetuação da extração destas matérias-primas. Ademais, a inércia do Estado permanece também para 0 direcionamento de políticas voltadas à extração do babaçu, pois, tornou-se comum afirmar a não valorização desta atividade por conta da expansão das pastagens. Não podemos negar esta premissa, mas também não podemos tornar essa dualidade como única, uma vez que o Estado possui grande parte da parcela de promoção destes conflitos e não podemos isentá-lo das ações, pois o Estado está alinhado aos objetivos da grande pecuária, e ele é fator preponderante.

A silvicultura, atividade voltada para o desenvolvimento e povoação florestal que na maioria das vezes visa o mercado, é uma atividade estritamente ligada a grandes estabelecimentos. No Maranhão, observamos uma produção voltada a lenha concentrada nos municípios de Feira Nova do Maranhão e Sambaíba, na microrregião Gerais de Balsas.

O carvão vegetal ainda é bastante utilizado pelas famílias camponesas, assim como para fins industriais a exemplo da produção siderúrgica e nas olarias. Seu uso se sobressai nos municípios de Bom Jardim e Bom Jesus das Selvas na microrregião de Pindaré, e em Açailândia e Itinga do Maranhão, inseridos na microrregião de Imperatriz.

A madeira em tora para papel e celulose está concentrada no extremo oeste do estado, na microrregião de Imperatriz. O suprimento de madeira visa abastecer, sobretudo, a fábrica da Suzano Papel e Celulose em Imperatriz, uma das mais modernas plantas do ramo no Brasil e no mundo. Os quatro municípios em ordem de produção são: Açailândia, São Pedro da Água Branca, Itinga do Maranhão e Cidelândia. Na Prancha 5 estão espacializadas a silvicultura relacionada a lenha, carvão vegetal e madeira em tora para papel e celulose. 
Prancha 5 - Silvicultura - 2017

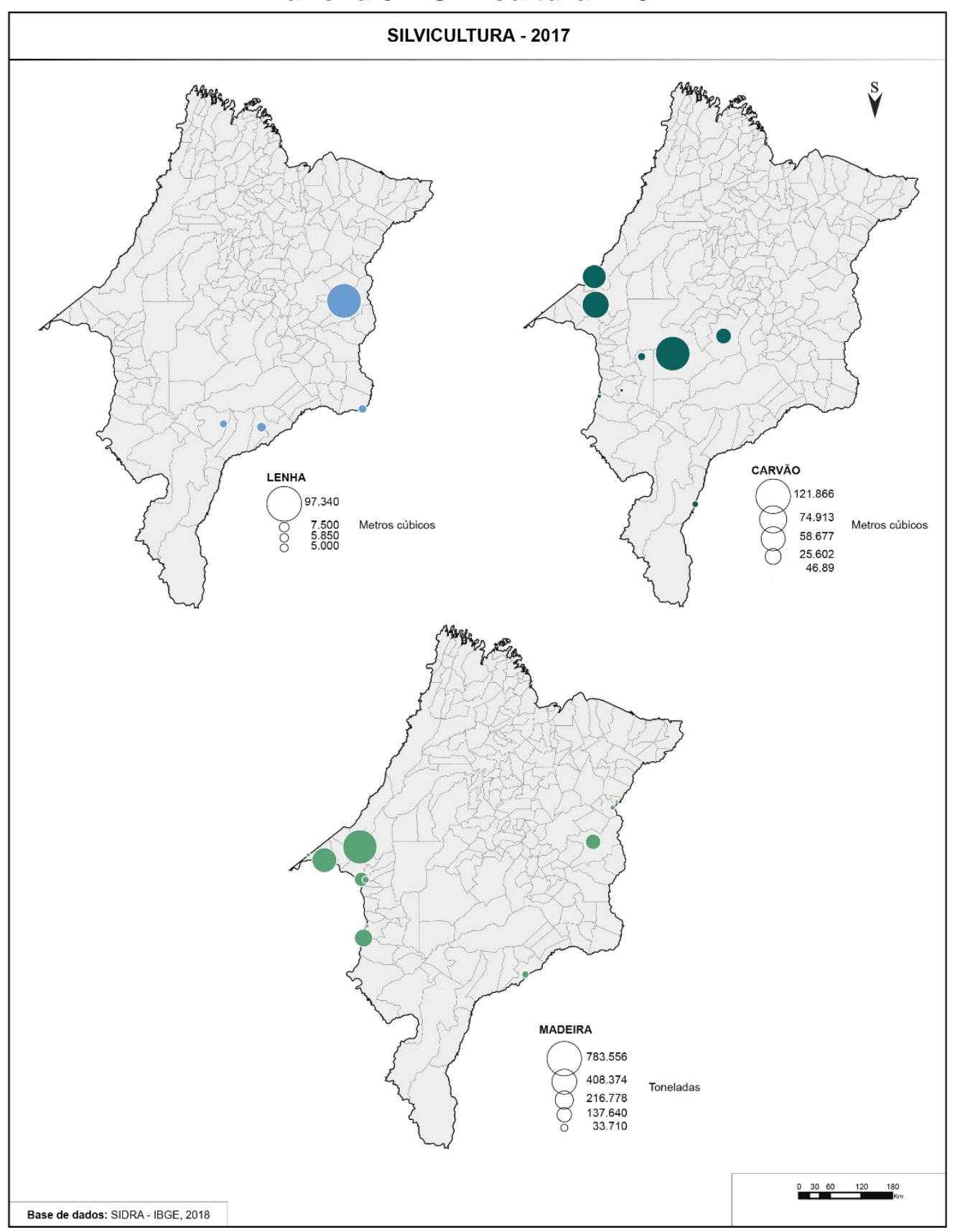

Diferentemente das outras atividades, a silvicultura especializa-se no Maranhão, mas de forma pontual e direcionada. Este direcionamento não é casual, pois conforme Mesquita (2018), a produção de grãos e a silvicultura aproveitam-se das políticas liberalizantes para sua expansão. Entender esta espacialização da monocultura parte do entendimento do capitalismo periférico, onde o Maranhão e o Brasil se encontram, ou seja, a dinâmica do capital periférico é diferente do capitalismo central. Conforme Smith (1988), que resgata as reflexões de um dos teóricos do subdesenvolvimento, Samir Amin, e aponta a acumulação autocentralizada, o desenvolvimento que gira em torno da produção de "bens de capital" e do incentivo de consumo em massa, como partes integrantes do capitalismo 
central, em contrapartida, o capital periférico conhece a produção para a exportação e o consumo de bens de luxo como base da economia, a consequência disto é uma estrutura essencialmente desequilibrada.

Assim, enquanto Maranhão, após estas diferenciações não demoramos muito a nos reconhecermos enquanto local do capitalismo periférico, principalmente no que tange a nossa produção para a exportação. Partindo disto, a instalação de empresas que praticam a silvicultura parte do preâmbulo dos clichês do desenvolvimento, progresso, emprego e renda, onde nada mais representa outra forma de acumulação do capital nacional e estrangeiro que também se valem da "atratividade do território" proposta pelos governos, em outras palavras, a exclusão social é parte das transformações locais decorrentes do livre acesso, posse e uso da terra, na destruição da biodiversidade, na concentração da terra e da renda (MESQUITA, 2018).

\section{A violência contra camponeses e trabalhadores rurais}

Como demonstrado anteriormente, a estrutura produtiva agrícola maranhense é bastante diversificada, sobressaindo em termos de valor da produção, as lavouras temporárias, por meio da produção de grãos, sobretudo a soja. No entanto, é importante destacar que o processo de expansão territorial de monoculturas ligadas ao agronegócio não se dá de forma harmoniosa, gerando em muitos casos conflitos territoriais e violências no campo. Os conflitos e a violência no campo persistem como resultado da implantação de um modelo agropecuário "moderno" de uma sociedade profundamente excludente e desigual. A expansão desse modelo no Brasil contraria as afirmações dos seus defensores, que veem nele uma revolução pacífica, quando na realidade se observa o agravamento do problema agrário e a manutenção da violência no meio rural (SAUER, 2008, p.239).

O campo maranhense no limiar do século XXI tem sido marcado pela intensificação, concentração e aumento da violência, ligada a concentração e centralização de poder, criando um estado de tensão para as famílias que vivem nas regiões de fronteira. Neste trabalho estamos considerando situações de violência às questões que envolvem ameaças de morte, tentativas de assassinatos e assassinatos.

O gráfico 2 apresenta os casos de violência registrados pela CPT envolvendo distintos sujeitos sociais no campo maranhense no período de 2001 a 2017. Com 
relação às ameaças de morte observa-se que os anos de maior ocorrência desse tipo de violência foram os anos de 2003 (104 registros), 2011 (com 116) e 2017 que apresentou um total de 106 episódios. No que tange aos casos de assassinatos, o ano de 2016 ganhou destaque com o maior número de ocorrências, 13 no total. $\mathrm{E}$ por último, as tentativas de assassinato, os registros da CPT indicam que o ano de 2017 foi aquele que se sobressaiu em relação aos demais, com 65 casos registrados.

\section{Gráfico 2 - Violência no Campo Maranhense (2001 - 2017)}

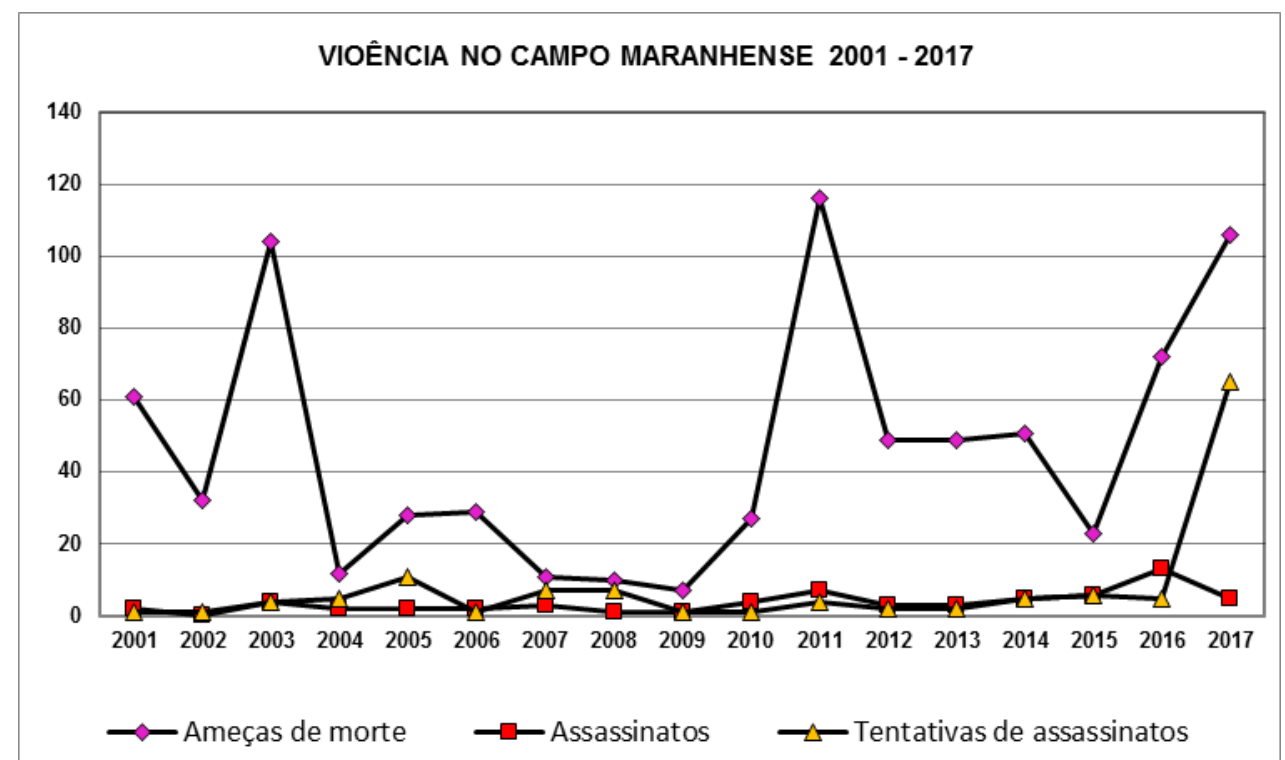

Fonte: CPT, 2018.

Como forma de melhor analisar os dados disponibilizados pela CPT, fizemos a representação dessas informações por meio da Figura 06. A Prancha 6 apresenta a espacialização dessas formas de violência no ano de 2017, nos dando uma dimensão da quantidade de sujeitos envolvidos nesses casos de violência, assim como, os principais agentes sociais envolvidos. 


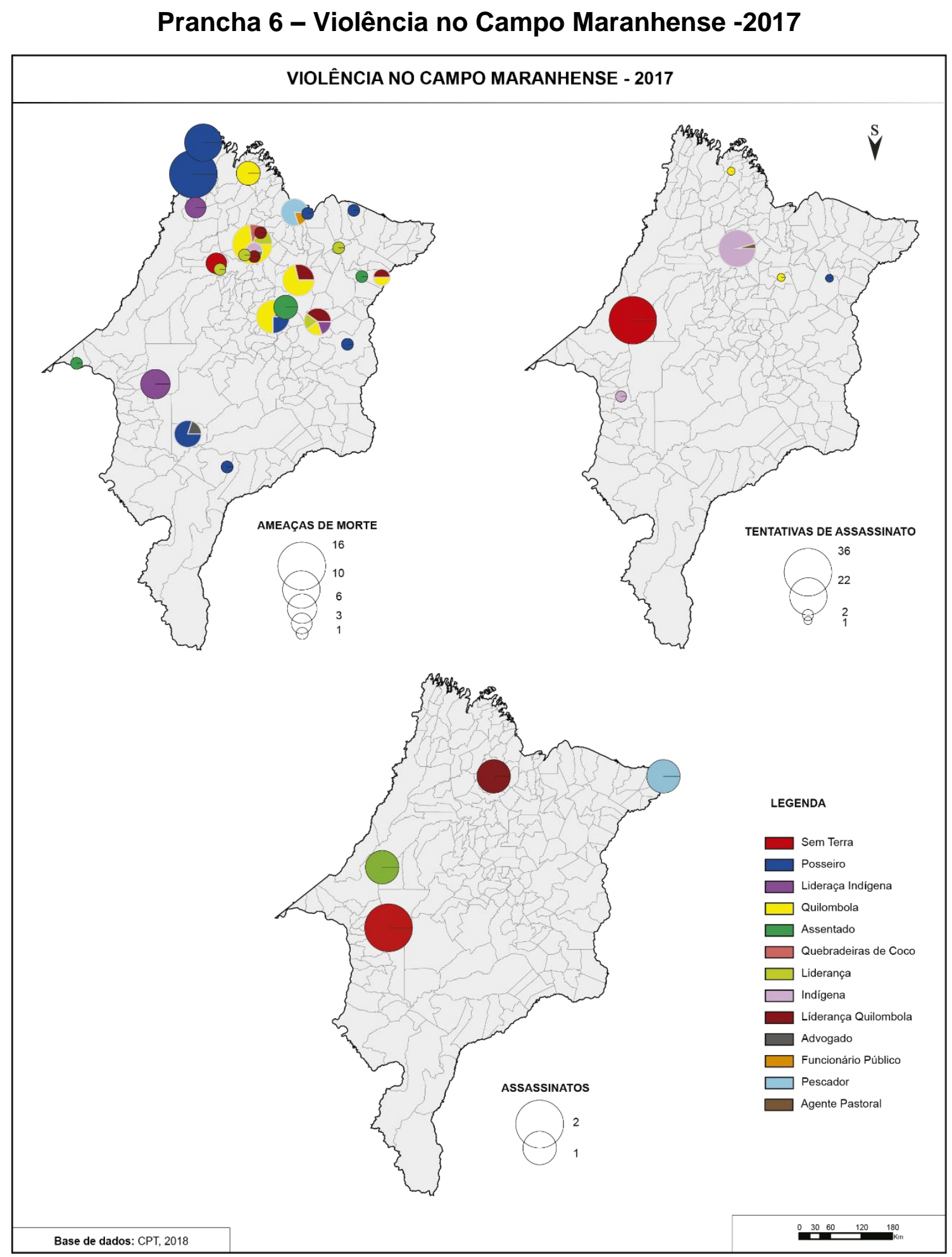

Nesse contexto, observa-se que os casos de violência envolvendo ameaças de morte, estão concentrados, sobretudo, na região norte do território maranhense, tendo como agentes sociais envolvidos notadamente quilombolas, posseiros e também assentados. A região norte do Maranhão tem se configurado como uma área de concentração da violência. Nessa região a presença de assentamentos de reforma agrária é bastante significativo, assim como, comunidades remanescentes 
de quilombos e indígenas, cujo processo de enfrentamento ao latifúndio tem resultado em inúmeros casos de violências.

Além da região norte, observa-se também uma quantidade expressiva de situações de ameaças de morte na parte leste do Maranhão. Alude-se que essa região em questão, a partir dos anos 2000 , passa a ganhar destaque na produção de grãos, principalmente a soja (CARNEIRO, 2008; GASPAR, 2013). Tal situação foi responsável pela eclosão de situações conflituosas entre produtores de soja, assentados e quilombolas (ALMEIDA, 2017). Convém ressaltar ainda que a expansão da produção de soja para a região leste maranhense foi responsável também pelo deslocamento espacial das áreas de conflitos no estado que, nos anos 1980 concentravam-se nas regiões centro e oeste do estado (SODRÉ, 2017).

Com relação às tentativas de assassinato observa-se que os registros ficaram circunscritos principalmente à parte oeste e norte do estado, envolvendo notadamente sem terras e indígenas. Em relação ao oeste maranhense, mencionase que esta região foi palco de intensos conflitos pela terra no processo de ocupação da Amazônia Maranhense durante a década de 1980, conforme aponta Asselin (2009) nas disputas entre camponeses e latinfundiários, esses últimos quase sempre saíam vitoriosos, a partir de diversos meios ilegais, que variavam da falsificação de documentos até o uso da violência.

As ocorrências envolvendo assassinatos foram registradas principalmente nas regiões oeste e norte do Maranhão e envolveram agentes sociais como sem terra, liderança quilombola e assentados, demonstrando o intenso processo histórico de luta pela terra nessas áreas e a violência daí decorrente.

Um fato que chama atenção e vale a pena destacar se refere à parte sul do Maranhão - cuja estrutura produtiva agrícola está assentada na produção de commodities agrícolas - que como se pode observar na Figura 06, quase não há registros de violência no campo por parte da CPT. Nesse sentido, uma das explicações para tal situação pode está relacionada à consolidação do agronegócio nessa região desde os anos 1990.

\section{Considerações Finais}

Assim, podemos observar ao longo do texto onde não deixamos de dissociar a manutenção da estrutura fundiária para com a inserção e os movimentos de reprodução do capital no campo, além das consequências da violência decorrente 
desta configuração que se perpetua desde o tempo de Brasil Colônia e Brasil Império. Fato este que nos demonstra como o estado do Maranhão ao longo de seu período colonial apenas remodela suas estratégias econômicas em prol de um desenvolvimento capitalista, onde é justificado com sentimento de pertencimento a todos, mas que pelas suas políticas, o Estado mostra o quão está alinhado ao capitalismo.

A dependência externa do estado do Maranhão, como afirmamos anteriormente, segue o mesmo direcionamento de práticas na agricultura e sua modificação apenas está na substituição do produto demandado externamente. Pode parecer fácil descrever uma possível solução de uma profunda modificação na estrutura de produção agrícola ou até mesmo na estrutura fundiária (a busca pela Reforma Agrária ainda se faz presente nos anseios dos movimentos sociais), seja no Maranhão ou no Brasil, mas estas configurações estão intimamente ligadas a uma ótica global de existência do capitalismo, ou seja, o desenvolvimento desigual é parte integrante de áreas periféricas ao capital, com isto, a mobilidade do capital está no objetivo de áreas com alta taxa de lucro e de possibilidade de sua reprodução (SMITH, 1988).

Nesta perspectiva, a manutenção de um estado agroexportador, no Maranhão, nada mais representa do que estar suscetível aos momentos de crises do capital ou na diminuição da demanda externa pelo produto. Para tanto, falar da inércia do Estado perante a agricultura familiar apenas reitera ainda mais o fomento e a abertura de novas áreas de produção para a agricultura empresarial, ou seja, este modelo econômico de "colonizado" não contribui para a resolução ou minimização dos conflitos internos no país, principalmente na luta pela terra, em contrapartida, acentua cada vez mais as disputas desleais entre os pequenos agricultores e os grandes produtores.

A parte integrante de todas estas configurações socioespaciais está centrada nas atuações do Estado, ainda que seja condescendente em temas e/ou áreas específicas. O caráter do Estado é o principal motor para se observar o presente e projetarmos o futuro, onde diferentemente de um Estado neoliberal ou neodesenvolvimentista, o ultraliberalismo, atualmente no Brasil, segue os moldes de outros países imperialistas, tais como os Estados Unidos. Isto não apenas acena como acordos de cooperação, mas pode nos levar a um retrocesso parecido ao vivido na ditadura militar, ou seja, a priorização na expansão de áreas de produção e o aumento de regalias para os grandes produtores, principalmente do agronegócio, 
enquanto que a agricultura familiar, responsável por $70 \%$ do abastecimento das mesas dos brasileiros pode conviver com a estagnação ou diminuição dos programas sociais, além da criminalização dos movimentos sociais.

\section{REFERÊNCIAS}

ALMEIDA, Juscinaldo G. A luta na/pela terra frente à expansão da soja no município de Brejo - MA. 148f. Dissertação (Mestrado em Geografia) - Programa de Pós-Graduação em Geografia, Natureza e Dinâmica do Espaço. Universidade Estadual do Maranhão. São Luís, 2017.

AMARAL FILHO, Jair do. A economia política do babaçu: um estudo da organização da extrato-indústria do babaçu no Maranhão e suas tendências. São Luís: SIOGE, 1990.

ANDRADE, Manuel Correia de. Paisagens e problemas do Brasil. 4를 ed. - São Paulo: Brasiliense, 1973.

ANDRADE, Manuel Correia de. Ensaios sobre a Realidade Maranhense. São Luís, IPES, 1984.

ASSELIN, Victor. Grilagem: corrupção e violência em terras do Carajás. Imperatriz - MA: Ética, 2009.

BARBOSA, Zulene Muniz. Maranhão, Brasil: Lutas de classes e reestruturação produtiva em uma nova rodada de transnacionalização do capitalismo. São Luís: EDUEMA, 2006.

CARNEIRO, Marcelo. A expansão e os impactos da soja no Maranhão. In: SCHLESINGER, S.; NUNES, S. P.; CARNEIRO, M. S. (Orgs.). A agricultura familiar da soja na região Sul e o monocultivo no Maranhão: duas faces do cultivo da soja no Brasil. - Rio de Janeiro: FASE, 2008, p.75-143.

GASPAR, Rafael. O eldorado dos gaúchos: deslocamento de agricultores do Sul do País e seu estabelecimento no Leste Maranhense. São Luís: EDUFMA, 2013.

CASTRO, Josué de. Geografia da fome: o dilema brasileiro: pão ou aço. Rio de Janeiro: Edições Antares, 1984.

COMISSÃO PASTORAL DA TERRA (CPT). Conflitos no Campo Brasil. 2001. Goiânia: CPT Nacional, 2001 - 2018.

GIRARDI, Eduardo Paulon. Proposição teórico-metodológica de uma Cartografia Geográfica Crítica e sua aplicação no desenvolvimento do Atlas da Questão Agrária Brasileira. 2008. Tese (Doutorado em Geografia) - Faculdade de Ciências e Tecnologia, Universidade Estadual Paulista, Presidente Prudente, 2008.

MARX, Karl. Grundrisse: Manuscritos e econômicos de 1857-1858: Esboços da crítica da economia política. São Paulo: Boitempo, 2011. 792 p.

MESQUITA, Benjamin Alvino. “Intervenção governamental e transformação do setor agrícola”. In: MESQUITA, Benjamim A. O desenvolvimento desigual da agricultura: a dinâmica do agronegócio e da agricultura familiar. São Luís: EDUFMA, 2011. p. 37-49.

\section{A expansão da fronteira agrícola num cenário de globalização da}

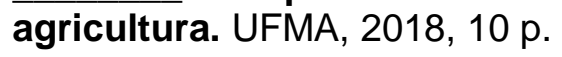


PAULA ANDRADE, Maristela de. A produção de carvão vegetal e o plantio de eucalipto no Leste Maranhense. In: CONCEIÇÃO, F. G. (Org.). Carajás: desenvolvimento ou destruição? Relatórios de Pesquisa. São Luís: CPT, 1995. p. 15-64.

PAULINO, Eliane Tomiasi. Geografia Agrária e Questão Agrária. In: Fernandes, B.M; MAQUES, M.I.M; SUZUKI, J.C. (Org.). Geografia Agrária: Teoria e Poder. São Paulo: Expressão popular, 2007. p.339 - 352.

SANTOS, Murilo. Fronteiras: a expansão camponesa no vale do Rio Caru. In: SANTOS, Murilo; PAULA ANDRADE, Maristela de. (Orgs.). Fronteiras: a expansão camponesa na Pré-Amazônia Maranhense. - São Luís: EDUFMA, 2009. p. 26-67.

SAUER, Sérgio. Conflitos agrários no Brasil. In BUAINAIN, Antônio Márcio. (Org). Luta pela terra, reforma agrária e gestão de conflitos no Brasil. Campinas: Editora da Unicamp, 2008. p.231 - 266.

SILVA, Erinaldo N. da. Conhecimento Local: saberes e práticas camponesas no cultivo da mandioca: o caso do povoado Vertente, Santa Quitéria do Maranhão. 149 f. (Monografia de Graduação em Ciências Sociais). Universidade Federal do Maranhão. São Luís, 2014.

SMITH, Neil. Desenvolvimento Desigual. Rio de Janeiro: Bertrand Brasil, 1988. 250 p

SODRÉ, Ronaldo B. O Maranhão Agrário: dinâmicas e conflitos territoriais. 222 f.

Dissertação (Mestrado em Geografia). - Programa de Pós-Graduação em Geografia, Natureza e Dinâmica do Espaço. Universidade Estadual do Maranhão. São Luís, 2017.

VELHO, Otávio G. Frentes de expansão e estrutura agrária: estudo do processo de penetração numa área da Transamazônica - 3ªe ed. - Manaus: UEA Edições, 2013. 180p.

WOLF, Eric R. Sociedades Camponesas. Rio de Janeiro: Ed. Zahar Editores, 1976.

As referências são alinhadas a esquerda. Com espaçamento simples entre linhas e separação uma linha em branco separando cada referência.

\section{NOTAS DE AUTOR}

\section{CONTRIBUIÇÃO DE AUTORIA}

Ronaldo Barros Sodré - Ficou especialmente responsável pela discussão, organização de dados e pela cartografia.

Juscinaldo Goes Almeida - Ficou especialmente responsável pelo desenvolvimento teórico-conceitual, análise de dados e procedimentos técnicos.

Igor Breno Barbosa de Sousa - Contribuiu na discussão teórico-conceitual, na coleta e análise de dados e na tradução do artigo.

Tibério Augusto dos Santos Sousa - Ficou responsável pela discussão, tradução do texto, design e revisão do texto

José Sampaio de Mattos Júnior - Contribuiu na discussão teórico-conceitual, revisão do manuscrito e aprovação da versão final.

\section{FINANCIAMENTO}

Fundação de Amparo à Pesquisa e ao Desenvolvimento Científico e Tecnológico do Maranhão (FAPEMA), Universidade Estadual do Maranhão (UEMA)

CONSENTIMENTO DE USO DE IMAGEM

Não se aplica

APROVAÇÃO DE COMITÊ DE ÉTICA EM PESQUISA

Não se aplica

CONFLITO DE INTERESSES

Não se aplica 


\section{LICENÇA DE USO}

Este artigo está licenciado sob a Licença Creative Commons CC-BY. Com essa licença você pode compartilhar, adaptar, criar para qualquer fim, desde que atribua a autoria da obra.

\section{HISTÓRICO}

Recebido em: 01-02-2019

Aprovado em: 30-03-2019 